\title{
Investigating seasonality, policy intervention and forecasting in the Indian gold futures market: a comparison based on modeling non-constant variance using two different methods
}

\author{
Rupel Nargunam ${ }^{1,2^{*}}$ (D, William W. S. Wei ${ }^{1}$ and N. Anuradha ${ }^{3}$
}

\section{${ }^{*}$ Correspondence:}

rupelnargunam25@gmail.

com

${ }^{1}$ Department of Statistical Science, Temple University, Philadelphia, PA 19122, USA Full list of author information is available at the end of the article

\begin{abstract}
This study focuses on the Indian gold futures market where primary participants hold sentimental value for the underlying asset and are globally ranked number two in terms of the largest private holdings in the physical form. The trade of gold futures relates to seasons, festivity, and government policy. So, the paper will discuss seasonality and intervention in the analysis. Due to non-constant variance, we will also use the standard variance stabilization transformation method and the ARIMA/GARCH modelling method to compare the forecast performance on the gold futures prices. The results from the analysis show that while the standard variance transformation method may provide better point forecast values, the ARIMA/GARCH modelling method provides much shorter forecast intervals. The empirical results of this study which rationalise the effect of seasonality in the Indian bullion derivative market have not been reported in literature.
\end{abstract}

Keywords: Gold futures prices, ARIMA models, Non-constant variance, ARCH and GARCH models, Box-Cox power transformation, Forecast errors

\section{Introduction}

A futures contract is an agreement between two parties to transfer ownership of an underlying asset at a fixed time in the future. It is a standardized contract, so the trade takes place through an exchange. The underlying quantity is physical gold in the case of a gold futures contract. This type of financial contract acts as an insurance to the investor as it allows them to benefit from favorable price movements and acts as a hedge against systemic financial risk (Kou et al. 2019) during unfavorable future price movements (Choudhry et al. 2015; Iqbal 2017). There is evidence that metals play an important role in diversifying risk (Beckmann et al. 2015; Lean and Wong 2015; Daskalaki et al. 2017; Alkhazali and Zoubi 2020). author(s) and the source, provide a link to the Creative Commons licence, and indicate if changes were made. The images or other third party material in this article are included in the article's Creative Commons licence, unless indicated otherwise in a credit line to the material. If material is not included in the article's Creative Commons licence and your intended use is not permitted by statutory regulation or exceeds the permitted use, you will need to obtain permission directly from the copyright holder. To view a copy of this licence, visit http:// creativecommons.org/licenses/by/4.0/. 
Forecasting futures prices is an integral component of a profitable futures trading strategy. In this respect, this paper uses one of the most popular methods for forecasting and econometric analysis, namely, ARIMA models (Box and Jenkins 1970; Al-Shaib 2006; Box et al. 2016; Guha and Bandyopadhyay 2016; Challa et al. 2018; Mallikarjuna and Rao 2019; Challa et al. 2020; Dong et al. 2020). The effects of seasonality are prevalent in the gold market (Ball et al. 1982; Ma 1986; Lucey and Tully 2006; Wang et al. 2019; Xiao and Maillebuau 2020) and are attributed to the Halloween effect (Bouman and Jacobsen 2002; Zhang and Jacobsen 2013; Pariyaprasert and Boonchuaymetta 2018; Schmidbauer and Rosch 2018), the calendar effect (Jain 2019), the festival season in India (Source: World Gold Council report), hours of daylight (Kamstra et al. 2003), and the autumn effect (Baur 2013).

Behavioural issues such as investor sentiment play an important role in gold prices (Aggarwal and Lucey 2007). Investment in gold has always been of great sentimental value to Indians due to cultural relevance and its objectification as a secure financial investment. Consequently, India ranks second largest in private gold holdings (Source: NITI Aayog report). The position of a major consumer is strengthened when the domestic economic need is linked with the international market for efficient price discovery and risk management. The presence of an established spot market provides members in the Indian value chain an opportunity to offset price risk through the futures market. The gold futures market allows investors to take positions by paying small initial margins, yielding higher returns, and the difference can be invested in risk-free government bonds. This additional incentive to invest in returns with zero risk, is possible when holding a portfolio containing the gold futures contract, unlike with equity investments and gold Exchange-Traded Funds (ETFs). The role of gold as a stabilizing force in the financial system during market shocks (Baur and McDermott 2010, 2016) highlights the need to investigate the volatility properties of the asset. Understanding and explaining the behavior of commodity volatility is imperative as it is useful in designing optimal hedging strategies for derivatives such as futures and options (French et al. 1987; Chou 1988; Kocaarslan et al. 2017; Shakil et al. 2018; Mo et al. 2018). Analyzing the residuals after fitting an ARIMA model may suggest the need for volatility models (Ping et al. 2013; Todorova 2017) and volatility forecasting to aid investment decisions (Samouilhan and Shannon 2008; Thupayagale 2010; Kumar 2014; Mukherjee and Goswami 2017; Emenogu et al. 2020).

In India, trading in gold futures began in 2003 and the derivative contract was initially listed in the Multi Commodity Exchange of India (MCX) and launched under the commodity derivatives segment in the National Stock Exchange (NSE) and Bombay Stock Exchange (BSE) in 2018. Therefore, MCX accounts for 95\% of the trade. The spot price on the MCX for the gold contracts is arrived at from polling a panel of representatives from the value chain of the physical market, with ex-polling conducted twice in a day (12.15 pm to $12.45 \mathrm{pm}$ and $4.00 \mathrm{pm}$ to $4.30 \mathrm{pm}$ ). The price is ex-Ahmedabad, which is based on the location of delivery, and on the lower tax structure, although the latter has become irrelevant after the imposition of the Goods and Service Tax (GST) in 2017. The price excludes GST and any other additional tax.

The trade volumes in gold futures fell to half and have remained stagnant in the last five years. This is due to the imposition of the Commodities Transaction Tax (CTT) of 
0.01\% in the 2013-2014 Union Budget. While the imposition of a transaction tax on the commodities futures market reduces speculative trading, it may not be able to reduce price volatility in futures or spot markets (Edwards 1993). In the Indian context, it is observed that the transaction tax will be a burden on the operators in the commodity market and act as a deterrent of entry to hedgers who may choose to shift to illegal platforms (Pavaskar and Ghosh 2008). The liquidity in the Indian commodity derivatives market started recovering in the first half of 2018-2019 from a steady decline during 2015-2018. A report published in the last quarter of FY 2019-2020 showed that returns from Indian gold funds were up $27 \%$ in the last one year, and up $11.93 \%$ in the last three years (Source: The Economic Times) This evidence suggests that investment in Indian gold investment products is a good portfolio diversification option and investment analysts and fund managers may be tempted to allocate more than the prudential $10 \%$. Therefore, our study is aimed to assist fund managers by modelling the volatility using time series forecasting models used in the estimation of Value at Risk (VaR), which is a measure of risk of loss for investments.

From the above introduction about the Indian gold market, we see the importance of finding suitable methods of analyzing this time series and the impact of seasonality, intervention, volatility, and forecasting. Thus, Sect. 2 will introduce seasonal time series models, an intervention test, and methods for describing non-constant variances. Section 3 discusses forecast performance of different time series methods, and Sect. 4 provides concluding remarks.

\section{Modeling methodology}

In this paper, we use a time series approach to build a statistical model on a nonhomogeneous, nonstationary time series after taking a proper degree of differencing and variance stabilizing transformations. In our preliminary analysis, we plot the time series, autocorrelation function and partial autocorrelation function for the monthly data to observe the presence of seasonality. Based on the results of our preliminary analysis, we construct models to accommodate the effects of the seasonality and intervention present in the series. However, for forecasting comparison and inference, we use only those models whose parameters are statistically significant. Further, the error distribution for the proposed model with non-constant variance is also examined and the results are tabulated.

The objective of this paper is to compare methods used to forecast future prices and to suggest the optimal method which is useful for practitioners. To obtain meaningful results through prediction, modelling the historical evolution of the series through time is imperative. Therefore, we use a time series approach to incorporate the distinctive features of this data series into model building.

Let $Z_{t}$ be a sequence denoting the monthly time series under analysis. The data used is the closing price of the derivative contract titled Multi Commodity Exchange of India Gold Commodity Future Continuation 1 (RIC: MAUc1) and is obtained from Thomson Reuters Eikon platform for 14 years from January 2005 to January 2019. It is a time series of closing price considering the rollover of the contracts on the fifth day of the contract expiry month. The trading unit is $1 \mathrm{~kg}$, and the quotation value is $10 \mathrm{~g}$. The data has been converted into a monthly series. So, the time unit $t$, used in this analysis is months. The 
currency denomination used to represent the closing price is the Indian Rupee. The whole data set is from January $2005(t=1)$ to January $2019(t=169)$ as shown in Fig. 1. We will use the first 156 observations for modeling analysis and the remaining observations for forecast comparison.

From Fig. 1, we see that the monthly data has an increasing trend. However, we are interested in analyzing if the seasonal pattern observed in the gold spot market is evident in the gold futures market, and in non-stationarity of the price series. We plot the autocorrelation and partial autocorrelation functions of the seasonally differenced monthly series to confirm our claim on seasonality. The effect of seasonality is evident with seasonal period, $s=12$, in the plots shown below in Fig. 2 .

Subsequently, we carry out the well-known augmented Dickey-Fuller (ADF) test (Dickey et al. 1984) to investigate the presence of a unit root in a seasonal time series. The result is given in Table 1, with p-values less than 0.05 indicating both regular differencing and seasonal differencing are needed.

A good time series modelling method is the well-known Box-Jenkins multiplicative seasonal ARIMA model $(p, d, q) \times(\mathrm{P}, \mathrm{D}, \mathrm{Q})_{s}$

$$
\Phi_{P}\left(B^{s}\right) \phi_{p}(B)(1-B)^{d}\left(1-B^{s}\right)^{D} \dot{Z}_{t}=\theta_{q}(B) \Theta_{Q}\left(B^{s}\right) a_{t},
$$

where (i) $\boldsymbol{\phi}_{\boldsymbol{p}}(\boldsymbol{B})$ and $\boldsymbol{\theta}_{\boldsymbol{q}}(\boldsymbol{B})$ are the regular autoregressive and moving average polynomials of order $p$ and $q$ respectively, $\boldsymbol{\Phi}_{\boldsymbol{P}}\left(\boldsymbol{B}^{\boldsymbol{s}}\right)$ and $\boldsymbol{\Theta}_{\mathbf{Q}}\left(\boldsymbol{B}^{\boldsymbol{s}}\right)$ are the seasonal autoregressive

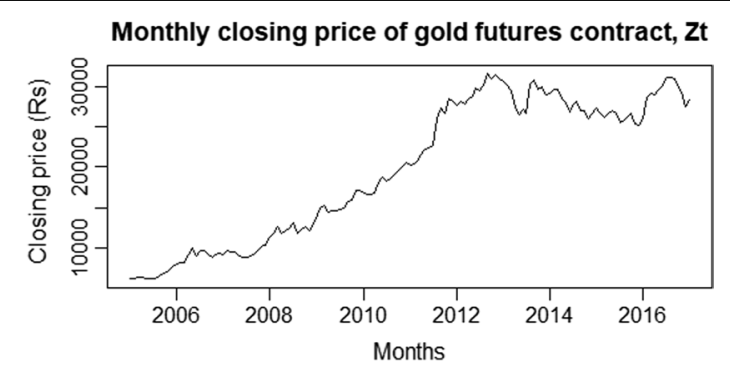

Fig. 1 Plot of the monthly price series, $Z_{t}$
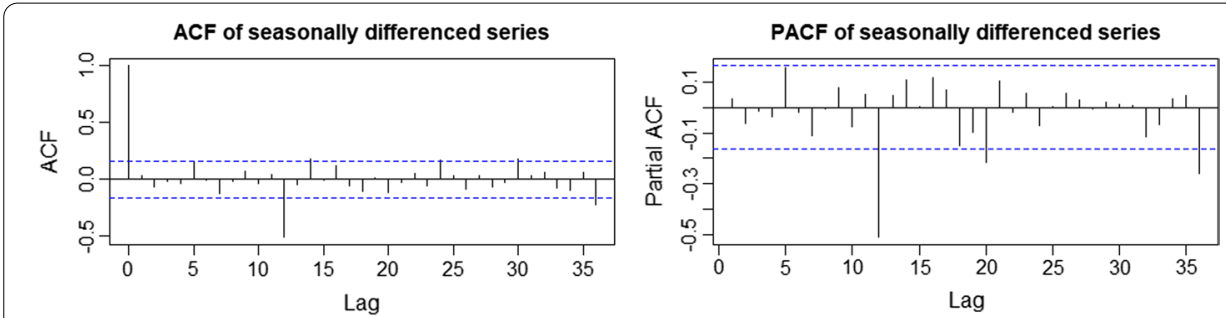

Fig. 2 Plot of autocorrelation and partial autocorrelation of seasonally differenced gold futures price series

Table 1 Unit root test P-values for gold futures price series

\begin{tabular}{llcc}
\hline Series name & Original & First difference & Seasonal difference \\
\hline Gold futures, $Z_{t}$ & 0.9242 & $<0.01$ & $<0.01$ \\
\hline
\end{tabular}


and moving average polynomials of orders $P$ and $Q$ respectively, the sub index $s$ refers to the seasonal period; (ii)

$$
\dot{Z}_{t}= \begin{cases}Z_{t}-\mu, & \text { if } d=D=0, \\ Z_{t}, & \text { otherwise, }\end{cases}
$$

where $\mu$ is the mean of the stationary $Z_{t}$; and (iii) $a_{t}$ is assumed to be the sequence of independent normally distributed random variables with zero mean and constant variance $\sigma_{a}^{2}$.

A simple way to find whether a series has a constant variance is to check the plot of residual squares after a preliminary model fitting. The following Fig. 3 of the residual squares after a preliminary ARIMA model fitting clearly shows the variance is not constant.

There are two approaches to solve the non-constant variance problem: The first approach is the power transformation.

$$
T\left(Z_{t}\right)=\frac{Z_{t}^{\lambda}-1}{\lambda}
$$

introduced by Box and Cox (1964), where in practice the value of $\lambda$ is often chosen from the set $\{1,0.5,0,-0.5,-1\}$ as the one that yields a model with the minimum Akaike Information Criterion (AIC) and/or Bayesian Information Criterion (BIC).

The other approach is the one first proposed by (Bollersev 1986), where Eq. (1) is rewritten as

$$
\Phi_{P}\left(B^{s}\right) \phi_{p}(B)(1-B)^{d}\left(1-B^{s}\right)^{D} \dot{Z}_{t}=\theta_{q}(B) \Theta_{Q}\left(B^{s}\right) n_{t},
$$

and we have the more general error process

$$
n_{t}=\sigma_{t} e_{t},
$$

where $e_{t}$ are i.i.d random variables with zero mean and variance one, independent of past realizations of $n_{t-i}$,

$$
\sigma_{t}^{2}=\theta_{0}+\phi_{1} \sigma_{t-1}^{2}+\cdots+\phi_{r} \sigma_{t-r}^{2}+\theta_{1} n_{t-1}^{2}+\cdots+\theta_{s} n_{t-s}^{2}
$$

and the roots of $\left(1-\phi_{1} B-\ldots-\phi_{r} B^{r}\right)=0$ are outside the unit circle. To guarantee $\sigma_{t}^{2}>0$, we assume that $\theta_{0}>0$ and that $\phi_{i}$ and $\theta_{j}$ are nonnegative. The model in (4) with the

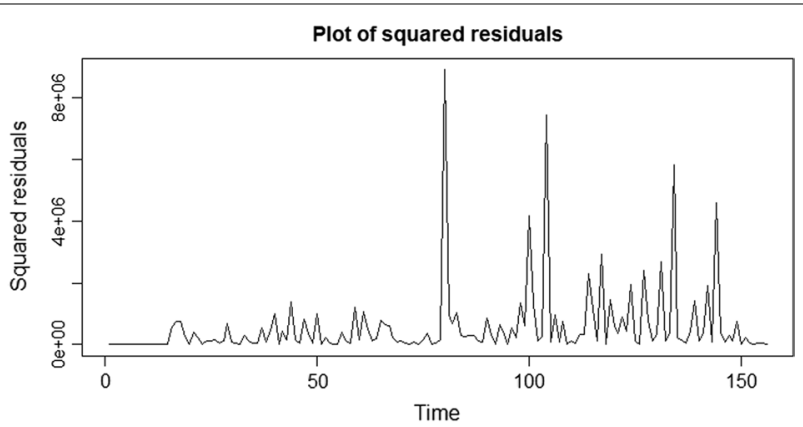

Fig. 3 Plot of the residual squares of model in Eq. (11) from preliminary model fitting 
Table 2 Power transformation for $Z_{t}$

\begin{tabular}{lllll}
\hline$\lambda$ & Log likelihood & $\begin{array}{l}\text { Root mean square } \\
\text { error (RMSE) }\end{array}$ & $\begin{array}{l}\text { Akaike information } \\
\text { criterion, (AIC) }\end{array}$ & $\begin{array}{l}\text { Bayesian } \\
\text { information } \\
\text { criterion, (BIC) }\end{array}$ \\
\hline 1.0 & -1263.81 & $1,534,533.01$ & 2539.62 & 2557.92 \\
0.5 & -1249.57 & $1,517,748.87$ & 2511.14 & 2529.44 \\
0.0 & -1249.58 & $1,591,506.86$ & 2511.17 & 2529.46 \\
-0.5 & -1266.58 & $1,387,536.15$ & 2545.17 & 2563.47 \\
-1.0 & -1299.56 & $1,320,672.06$ & 2611.11 & 2629.41 \\
\hline
\end{tabular}
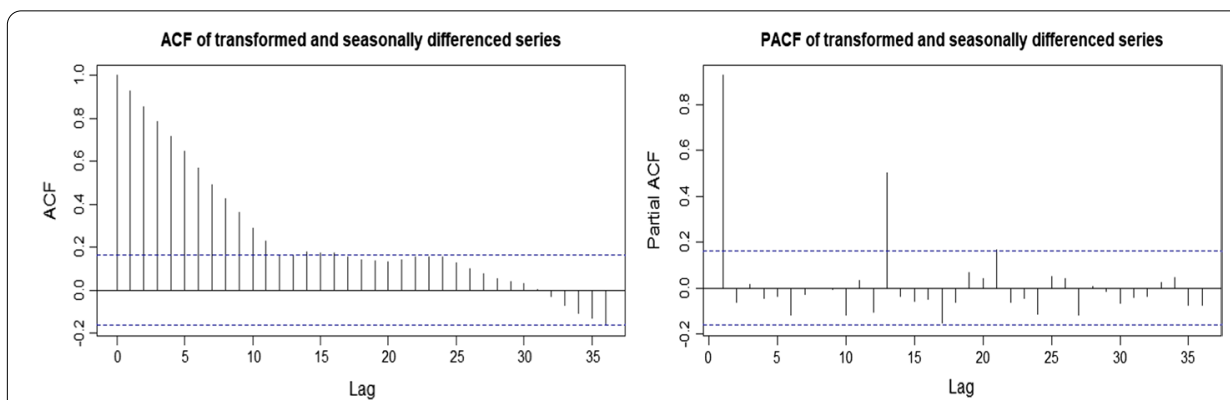

Fig. 4 Plot of autocorrelation and partial autocorrelation of transformed and seasonally differenced gold futures price series

property in (5) is known as the generalized autoregressive conditional heteroscedasticity (GARCH) model of order $(r, s)$ and is denoted by GARCH $(r, s)$ (Wei 2006) (Chapter 15).

We will now illustrate the two approaches in the following subsections.

\section{The power transformation approach}

In this subsection, we apply the power transformation function given in Eq. (2) to stabilize the non-constant error variance. Based on the minimum AIC and/or BIC given in Table 2 obtained from a SAS program, it suggests a square root transformation of the series for a constant variance.

\section{A seasonal ARIMA model for the square root transformed series}

After regular and seasonal differencing, the autocorrelation and partial autocorrelation plots of the transformed series shown in Fig. 4 suggests a seasonal ARIMA model of order $(3,1)$. The model can then be written as follows

$$
\left(1-\Phi_{1} B^{12}-\Phi_{2} B^{24}-\Phi_{3} B^{36}\right)(1-B)\left(1-B^{12}\right) \sqrt{Z_{t}}=\left(1-\Theta_{1} B^{12}\right) a_{t},
$$

where (1) $t$ ranges from 1 to 156 , (2) $s=12,24,36$, (3) $B$ is the backshift operator, (4) $a_{t}$ is assumed to be a sequence of independent normally distributed random variables with zero mean and constant variance $\sigma_{a}^{2}$.

The parameter estimates of the coefficients to the above fitted model are obtained. After removing the non-significant seasonal autoregressive coefficients associated with $B^{12}$ and $B^{24}$, the obtained model is: 


$$
\left(1+\underset{(0.0912)}{0.2591} B^{36}\right)(1-B)\left(1-B^{12}\right) \sqrt{Z_{t}}=\left(1+\underset{(0.0888)}{0.7455} B^{12}\right) a_{t} \text {, }
$$

and $\hat{\sigma}_{a}^{2}=7.246$. The residual autocorrelations and partial autocorrelations shown in Fig. 5 indicate the adequacy of the model.

\section{Check intervention on square root transformed series}

Intervention analysis is a useful technique to study the effect of an external event that causes a level shift in the time series (Box and Tiao 1975). In our study, we will check the effect of the tax known as CTT on the series, which is represented as a step function and included in the model. In this section, the impact of CTT on the transformed series is examined.

The model with the intervention is:

$$
\sqrt{Z_{t}}=\omega_{o} I_{t}+\frac{\left(1-\Theta_{1} B^{12}\right)}{(1-B)\left(1-B^{12}\right)\left(1-\Phi_{1} B^{12}-\Phi_{2} B^{24}-\Phi_{3} B^{36}\right)} a_{t},
$$

where (1) $\omega_{o}$ represents the initial impact of CTT which is also felt during the period after introduction, (2) the effect of intervention represented by $I_{t}$ is expected to produce a step change from March 2013, which is the time of announcement of the tax and is denoted by $t=100$ in our dataset

$$
I_{t}=\left\{\begin{array}{l}
0, t \leq 100 \\
1, t>100
\end{array}\right.
$$

and (3) $a_{t}$ is assumed to be a sequence of independent normally distributed random variables with zero mean and variance one.

The estimation result is given below:

$$
\sqrt{Z_{t}}=\frac{(1+5916}{(2.5279)} I_{t}+\frac{(0.7486}{(1-B)\left(1-B^{12}\right)\left(1+\underset{(0.0915)}{0.2572} B^{36}\right)} a_{t} \text {, }
$$

with all parameters being significant except the one pertaining to the intervention variable and coefficients of the seasonal autoregressive operators $B^{12}, B^{24}$ and $\hat{\sigma}_{a}^{2}=7.221$. The residual autocorrelations and partial autocorrelations indicate the adequacy of the model. From the estimates of model fitting, we see that the effect from intervention is
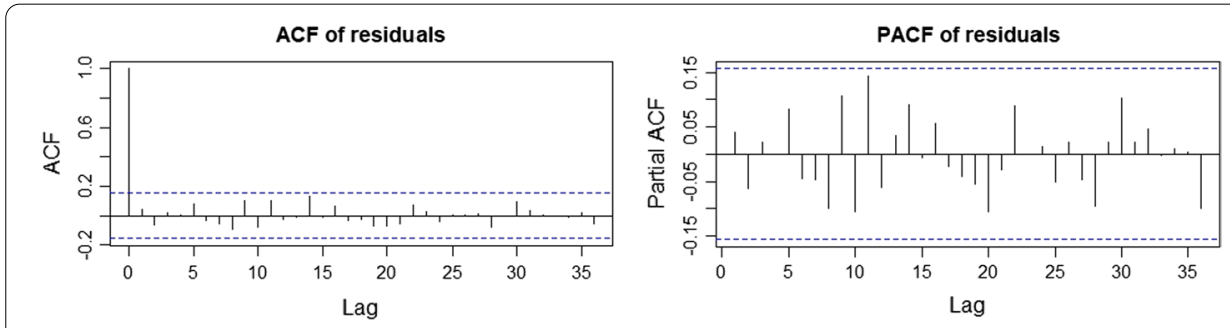

Fig. 5 The plot of autocorrelation and partial autocorrelation of residuals from model in Eq. (7) 
negative but not statistically significant for a significance level of $5 \%$ or for any of the commonly used significance levels, since its p-value $=\mathrm{P}\left(Z<\frac{-1.5916}{2.5279}\right)=0.2645$, and the commonly used level at the final conclusion is $5 \%$. Therefore, we omit the variable for tax intervention $I_{t}$, and use Eq. (7) as our final chosen model for the square root transformed series.

\section{An ARIMA/GARCH modelling approach}

In this section, after fitting a time series model for the gold future prices, we will fit an ARCH/GARCH model to model its error variance. We refer readers to existing literature that uses similar methods of analysis and discusses the reliability of results obtained through econometric software (McCullough and Vinod 1999; McCullough and Renfro 2000).

\section{A seasonal ARIMA model fitting}

As indicated earlier, in order to determine whether the series has a constant variance, we preliminarily fitted an ARIMA $(0,1,0) \times(3,1,1)_{12}$ model to the data set, which is based on its plot of autocorrelation and partial autocorrelation of the regularly and seasonally differenced series. The exact model form is given below:

$$
\left(1-\Phi_{1} B^{12}-\Phi_{2} B^{24}-\Phi_{3} B^{36}\right)(1-B)\left(1-B^{12}\right) Z_{t}=\left(1-\Theta_{1} B^{12}\right) n_{t},
$$

where (1) $t$ ranges from 1 to 156 , (2) $B$ is the backshift operator, (3) $n_{t}$ is assumed to be a sequence of independent normally distributed random variables with zero mean and non-constant variance, and both regular and seasonal differencing is order 1 with seasonal period of 12 .

The parameter estimates of the coefficients to the above fitted model are obtained and after removing the non-significant seasonal autoregressive coefficients associated with $B^{12}$ and $B^{24}$, the obtained model is:

$$
\left(1+\underset{(0.0885)}{0.2651} B^{36}\right)(1-B)\left(1-B^{12}\right) Z_{t}=\left(1+\underset{(0.0913)}{0.7280} B^{12}\right) n_{t} .
$$

The time dependent error variance will be discussed later.

\section{A seasonal ARIMA model with intervention}

In this subsection, we will check the effect of a CTT on the regular and seasonally differenced series. The model with the intervention is:

$$
Z_{t}=\omega_{o} I_{t}+\frac{\left(1-\Theta_{1} B^{12}\right)}{(1-B)\left(1-B^{12}\right)\left(1-\Phi_{1} B^{12}-\Phi_{2} B^{24}-\Phi_{3} B^{36}\right)} n_{t},
$$

where $n_{t}$ is assumed to be a sequence of independent normally distributed random variables with zero mean and non-constant variance and the definitions of other terms are the same as those in (8).

The parameter estimates of the coefficients are obtained and it is observed that the seasonal autoregressive coefficients associated with $B^{12}$ and $B^{24}$ are not significant and 
hence they are omitted, and the parameters are re-estimated. The model in (12) with reestimated parameters is:

$$
Z_{t}=\frac{\left(1+\begin{array}{c}
0.7310 \\
(737.0918)
\end{array} B^{12}\right)}{(1-B)\left(1-B^{12}\right)\left(1+\underset{(0.0889)}{0.2623} B^{36}\right)} I_{t},
$$

with all parameters except the one pertaining to intervention variable being significant and the time dependent error variance will be discussed later. The residual autocorrelations and partial autocorrelations indicate the adequacy of the model.

From the estimates of model fitting, it is evident that the negative signs of the intervention parameter estimates show that the introduction of CTT reduced the gold futures prices but not quite significantly. The estimates of the intervention variable are not statistically significant, since its $p$ value $=P\left(Z<\frac{-437.8838}{737.7356}\right)=0.2764$, for the commonly used 5\% significance level. Therefore, we omit the intervention and simply use Eq. (11) in the further analysis.

\section{Volatility models for $n t$}

Here, we apply the general framework discussed at the beginning of this section to the squared residuals obtained from fitting the model given in Eq. (11). The autocorrelation and partial autocorrelation plots of the squared residuals of the model in Eq. (11) as shown in Fig. 6 suggest fitting a seasonal ARCH (2) model, with seasonal period $s=12$.

Based on the highest significant spike at lag 24 in the plot of the partial autocorrelation function, a seasonal ARCH (2) model with seasonal period 12 is fitted on the squared residuals of the model in Eq. (11).

The parameter estimates of the seasonal ARCH (2) model are obtained and after removing the non-significant seasonal autoregressive coefficient associated with $B^{12}$ the obtained model is:

$$
\begin{aligned}
& n_{t}=\sigma_{t} e_{t}, \\
& \sigma_{t}^{2}=\underset{(0.0724)}{0.4343} n_{t-24}^{2},
\end{aligned}
$$

where $e_{t}$ is assumed to be a sequence of independent normally distributed random variables with zero mean and variance one.
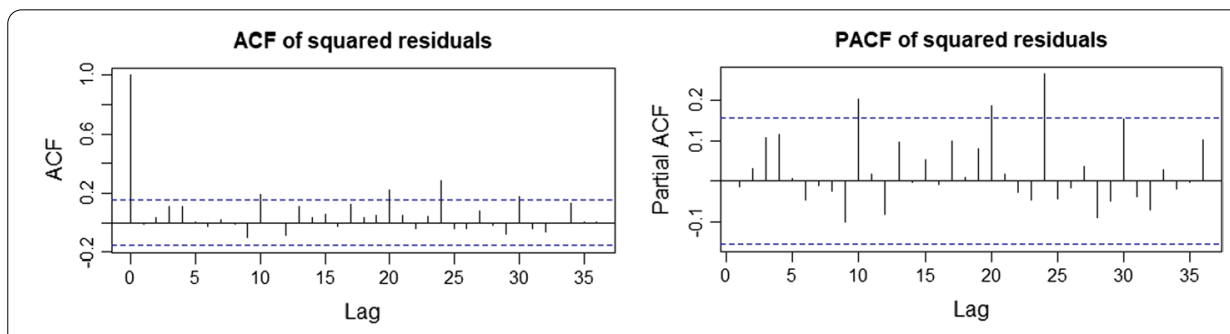

Fig. 6 The plot of autocorrelation and partial autocorrelation of the squared residuals from model in Eq. (11) 
So, for the gold futures prices, we have a seasonal ARIMA-GARCH model with its estimation results given below.

$$
\begin{aligned}
& \left(1+\begin{array}{c}
0.2651 \\
(0.0885)
\end{array} B^{36}\right)(1-B)\left(1-B^{12}\right) Z_{t}=\left(1+\underset{(0.0913)}{0.7280} B^{12}\right) n_{t}, \\
& n_{t}=\sigma_{t} e_{t} \\
& \sigma_{t}^{2}=\underset{(0.0724)}{0.4343} n_{t-24}^{2} .
\end{aligned}
$$

\section{Forecasts from price models and their performance}

The models from Eqs. (7) and (15) are used to forecast future values. The $l$-step ahead forecasts are calculated from the time origin $t=156$ as follows.

The $l$ - step ahead forecast equation for the model in Eq. (7) is

$$
\begin{aligned}
\hat{Y}_{156}(l)= & \hat{Y}_{156}(l-1)+\hat{Y}_{156}(l-12)-\hat{Y}_{156}(l-13)-0.2591 \hat{Y}_{156}(l-36) \\
& +0.2591 \hat{Y}_{156}(l-37)+0.2591 \hat{Y}_{156}(l-48)-0.2591 \hat{Y}_{156}(l-49) \\
& +E\left(a_{156+l} \mid Y_{156}, Y_{155}, \ldots\right)+0.7455 E\left(a_{156+l-12} \mid Y_{156}, Y_{155}, \ldots\right),
\end{aligned}
$$

where $Y_{t}=\sqrt{Z_{t}}$ and $a_{t}$ is the white noise series of independent $N\left(0, \sigma_{a}^{2}\right)$ random variables.

The $l$ - step ahead forecast equation for the model in Eq. (15) is

$$
\begin{aligned}
\hat{Z}_{156}(l)= & \hat{Z}_{156}(l-1)+\hat{Z}_{156}(l-12)-\hat{Z}_{156}(l-13)-0.2651 \hat{Z}_{156}(l-36) \\
& +0.2651 \hat{Z}_{156}(l-37)+0.2651 \hat{Z}_{156}(l-48) \\
& -0.2651 \hat{Z}_{156}(l-49)+E\left(n_{156+l} \mid Z_{156}, Z_{155}, \ldots\right) \\
& -0.7280 E\left(n_{156+l-12} \mid Z_{156}, Z_{155}, \ldots\right) .
\end{aligned}
$$

For comparison, the $l$-step ahead forecasts from Eq. (16) are converted to the degree of the original series by raising the values to the power 2 . This conversion also raises the value of the standard deviation by the power 2 and is used in calculating forecast error variances and the associated forecast limits to be discussed in Sect. 3.2 below.

The predicted future price values are compared with the actual values of the closing price of the derivative and the forecast errors are calculated as the difference between the actual values and the forecast values as follows.

$$
e_{l}=Z_{n+l}-\hat{Z}_{n}(l)
$$

where $n$ is the forecast origin, and $l$ is the lead time of the forecasts from the same origin. Further, the forecast measures are calculated to ascertain the model which provides better forecasts. The comparison is usually based on the following summary statistics, mean square error (MSE) and mean absolute percentage error (MAPE), which are the most popular measures for forecast accuracy and consequently used in model selection. MSE is scale dependent and MAPE is scale independent. 
Table 3 Comparison of actual values and forecast values between models (7) and (15) and their associated forecast errors

\begin{tabular}{lllllc}
\hline Lead time (Months) & Actual value (Rs.) & $\begin{array}{l}\text { Forecast from } \\
\text { model in (7) }\end{array}$ & Forecast error & $\begin{array}{l}\text { Forecast from } \\
\text { model in (15) }\end{array}$ & Forecast error \\
\hline Jan 2018 & $29,634.09$ & $28,912.17$ & 721.92 & $28,888.65$ & 745.44 \\
Feb 2018 & $30,392.9$ & $30,007.37$ & 385.53 & $29,938.32$ & 454.58 \\
Mar 2018 & $30,454.24$ & $30,014.46$ & 439.78 & $29,904.09$ & 550.15 \\
Apr 2018 & $31,113.81$ & $29,635.16$ & 1478.65 & $29,529.89$ & 1583.92 \\
May 2018 & $31,152.26$ & $29,515.09$ & 1637.17 & $29,361.16$ & 1791.1 \\
June 2018 & $30,845.57$ & $29,803.44$ & 1042.13 & $29,647.88$ & 1197.69 \\
July 2018 & $30,101.95$ & $30,114.03$ & -12.08 & $29,937.36$ & 164.59 \\
Aug 2018 & $29,710.23$ & $31,150.51$ & -1440.28 & $30,935.40$ & -1225.17 \\
Sept 2018 & $30,563.3$ & $31,498.75$ & -935.45 & $31,236.43$ & -673.13 \\
Oct 2018 & $31,659.86$ & $30,959.01$ & 700.85 & $30,662.91$ & 996.95 \\
Nov 2018 & $30,948.64$ & $31,199.12$ & -250.48 & $30,838.18$ & 110.46 \\
Dec 2018 & $31,412.55$ & $30,666.13$ & 746.42 & $30,252.24$ & 1160.31 \\
Jan 2019 & $32,067.91$ & $30,892.56$ & 1175.35 & $30,453.99$ & 1613.92 \\
\hline
\end{tabular}

Table 4 Forecast performance measures between models (7) and (15)

\begin{tabular}{lll}
\hline Forecast performance measure & Model in (7) & Model in (15) \\
\hline Mean square error, MSE & $942,935.2$ & $1,165,745$ \\
Mean absolute percentage error, MAPE & 2.73 & 3.05 \\
\hline
\end{tabular}

\section{Comparisons of forecast values}

The $l$-step ahead forecasts of Model (7) through Eq. (16) and Model (15) through Eq. (17) are computed. For comparison, forecast values and forecast errors are tabulated in Table 3 below.

It is evident that between the fitted models in Eqs. (7) and (15), the forecasts from the model in Eq. (7) are closer to the actual values than those from the model in Eq. (15) in eleven out of thirteen cases. The forecast performance measures for the fitted models can further be illustrated using the summary statistics in Table 4 .

The forecast measures between both models are coherent. The values of errors are lower for the model in Eq. (7) than the errors for the model in Eq. (15). This indicates a higher forecasting accuracy for model in Eq. (7), implying that it slightly outperforms the model in Eq. (15) in terms of forecast accuracy.

\section{Comparisons of forecast limits}

In time series modeling, we check the efficacy of our proposed model and its relevance to theory by forecasting. This, therefore, is an important application of time series analysis. In our study, we also want to investigate their associated forecast limits for the forecasts from both models.

When models in Eqs. (7) and (15) are used to compute forecasts using time series software like SAS or R, we can also calculate their associated forecast limits. For comparison, we have calculated the $95 \%$ forecast limits and the associated lengths of intervals 

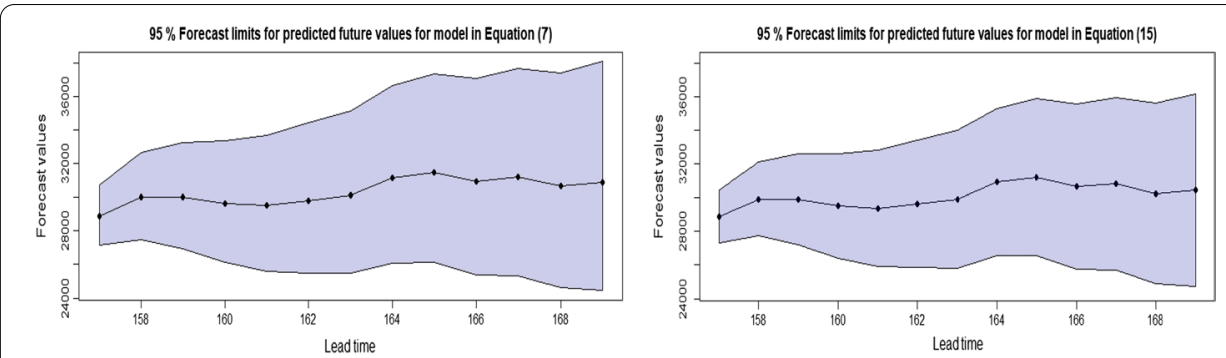

Fig. 7 The plot of 95\% Forecast limits for predicted future values for model in Eq. (7) and model in Eq. (15)

Table 5. $95 \%$ Forecast limits for predicted future values for model in Eq. (7) and model in Eq. (15)

\begin{tabular}{|c|c|c|c|c|c|c|c|c|}
\hline \multirow{2}{*}{$\begin{array}{l}\text { Lead time } \\
\text { (months) }\end{array}$} & \multicolumn{4}{|c|}{$95 \%$ forecast limits for the model in Eq. (7) } & \multicolumn{4}{|c|}{ 95\% forecast limits for the model in Eq. (15) } \\
\hline & $\begin{array}{l}\text { Lower } \\
\text { limit }\end{array}$ & $\begin{array}{l}\text { Predicted } \\
\text { value }\end{array}$ & $\begin{array}{l}\text { Upper } \\
\text { limit }\end{array}$ & $\begin{array}{l}\text { Length of } \\
\text { interval }\end{array}$ & $\begin{array}{l}\text { Lower } \\
\text { limit }\end{array}$ & $\begin{array}{l}\text { Predicted } \\
\text { value }\end{array}$ & $\begin{array}{l}\text { Upper } \\
\text { limit }\end{array}$ & $\begin{array}{l}\text { Length of } \\
\text { interval }\end{array}$ \\
\hline Jan 2018 & $27,145.07$ & $28,912.17$ & $30,734.98$ & 3589.91 & $27,338.53$ & $28,888.65$ & $30,438.78$ & 3100.25 \\
\hline Feb 2018 & $27,477.24$ & $30,007.37$ & $32,648.92$ & 5171.68 & $27,746.25$ & $29,938.32$ & $32,130.39$ & 4384.14 \\
\hline Mar 2018 & $26,930.74$ & $30,014.46$ & $33,265.29$ & 6334.55 & $27,219.42$ & $29,904.09$ & $32,588.76$ & 5369.34 \\
\hline Apr 2018 & $26,112.55$ & $29,635.16$ & $33,380.58$ & 7268.03 & $26,429.93$ & $29,529.89$ & $32,629.85$ & 6199.92 \\
\hline May 2018 & $25,599.67$ & $29,515.09$ & $33,709.02$ & 8109.35 & $25,895.32$ & $29,361.16$ & $32,826.99$ & 6931.67 \\
\hline June 2018 & $25,507.25$ & $29,803.44$ & $34,433.83$ & 8926.58 & $25,851.27$ & $29,647.88$ & $33,444.50$ & 7593.23 \\
\hline July 2018 & $25,463.04$ & $30,114.03$ & $35,154.92$ & 9691.88 & $25,836.55$ & $29,937.36$ & $34,038.16$ & 8201.61 \\
\hline Aug 2018 & $26,104.41$ & $31,150.51$ & $36,642.22$ & $10,537.81$ & $26,551.46$ & $30,935.40$ & $35,319.33$ & 8767.87 \\
\hline Sept 2018 & $26,129.74$ & $31,498.75$ & $37,369.05$ & $11,239.31$ & $26,586.57$ & $31,236.43$ & $35,886.28$ & 9299.71 \\
\hline Oct 2018 & $25,364.85$ & $30,959.01$ & $37,110.16$ & $11,745.31$ & $25,761.54$ & $30,662.91$ & $35,564.28$ & 9802.74 \\
\hline Nov 2018 & $25,322.34$ & $31,199.12$ & $37,688.58$ & $12,366.24$ & $25,697.59$ & $30,838.18$ & $35,978.78$ & $10,281.19$ \\
\hline Dec 2018 & $24,597.68$ & $30,666.13$ & $37,402.98$ & $12,805.3$ & $24,883.07$ & $30,252.24$ & $35,621.41$ & $10,738.34$ \\
\hline Jan 2019 & $24,435.55$ & $30,892.56$ & $38,105.71$ & $13,670.16$ & $24,734.05$ & $30,453.99$ & $36,173.94$ & $11,439.89$ \\
\hline
\end{tabular}

between upper and lower limits. The plots of the forecast limits along with predicted future values are given in Fig. 7, and the values are presented in Table 5.

\section{Concluding remarks}

This paper employs time series models to examine the gold futures market in India taking into account the seasonality prevalent in this market and the implementation of a new tax scheme, namely CTT.

The estimation results show that the parsimonious forecasting models without intervention variable provide a better fit to the gold futures data. It is observed that the coefficient of the intervention variable is negative, but the results from the analysis show that the parameter estimates of the intervention variable are not statistically significant. Therefore, the forecasts carried out in this study do not include the intervention variable. The decrease in price trend observed in Fig. 1 after 2013, shows the lack of financial literacy among the market participants with regard to the new tax regime that offers an income tax benefit and that the market was dominated by speculative traders. For the futures market to work, both hedgers and speculators are needed, and both play a crucial role. This highlights the need for stringent monitoring to avoid manipulation in futures markets. It also calls for the need to organize 
awareness programs advocating investment alternatives and their benefits. A recent empirical study on an emerging market shows how speculative capital movement is monitored to improve efficiency in the financial markets (Chao et al. 2019).

Market sentiments also play a major role in the Indian context, mainly due to the sentimental attachment to the underlying asset. Since India is a price taker due to the absence of domestic mining the fluctuations in gold spot price are to a greater extent influenced by macroeconomic variables. The world gold price is derived from the London price fix. China follows a similar benchmarking methodology to deciding the price, known as the Shanghai price fix or the Shanghai gold benchmark. In India, the Indian Bullion Jewelers Association (IBJA) publishes daily price for gold. However, there is a lack of transparency due to the absence of a regulatory framework to effectuate the Indian price fix or benchmark price for gold in the domestic currency (Indian rupees) for as low a denomination as one gram or ten grams of gold and calls to attention the need for an independent organization to oversee commercial gold trade.

In Table 3, we observe that according to the model in Eq. (7) and the model in Eq. (15), the price forecasts are increasing for first nine months, but are decreasing for next four months based on model in (15), however, the results from model in (7) is increasing in lead time $=10,11$ and subsequently decreases. The forecasts from the model in Eq. (15) suggests that the Indian gold futures market does not work in tandem with the gold spot market, suggesting the presence of "reverse autumn effect" in the gold futures market. This shows that the anomaly present in the spot market is not likely to be found in the derivative market. Therefore, gold futures is an effective hedge and an attractive investment option to investors who might want to include gold in their portfolio to hedge against the volatility in the spot market in case of a long position and also earn short sale profits due to prices moving in opposite directions in different markets. There may also be short windows for arbitrage due to the delay in convergence of basis (difference between spot and futures prices) due to market frictions. It is observed that the trade in the gold futures market has increased over the first quarter in 2018.

Since all actual values are contained in the $95 \%$ forecast limits, the forecasts from the fitted models suggest that the future values of the gold futures contract can be predicted from historical values with a certain degree of accuracy. Consequently, they can be used by fund managers and active investors to re-adjust their portfolio allocations.

The method used for determining the power transformation was carried out using SAS and the rest of the analysis in our study was carried out using R Studio software. The code for the same is available upon request to the authors.

\footnotetext{
Abbreviations

ARIMA: Auto Regressive Integrated Moving Average; NITI Aayog: National Institution for Transforming India (Aayog is the Hindi translation for Policy Commission); ETF: Exchange-Traded Funds; MCX: Multi Commodity Exchange; NSE: National Stock Exchange; BSE: Bombay Stock Exchange; GST: Goods and Service Tax; CTT: Commodities Transaction Tax; FY: Financial Year; VaR: Value at Risk; ADF: Augmented Dickey-Fuller; AIC: Akaike Information Criterion; BIC: Bayesian Information Criterion; ACF: Autocorrelation Function; PACF: Partial Autocorrelation Function; GARCH: Generalised Auto Regressive Conditional Heteroscedasticity; ARCH: Auto Regressive Conditional Heteroscedasticity; MSE: Mean Square Error; MAPE: Mean Average Percentage Error; IBJA: Indian Bullion Jewelers Association.
} 


\section{Authors' contributions}

This paper is a part of the research project sponsored by the Fulbright program. The research was carried out by Rupel Nargunam and was supervised by Dr. William W. S. Wei, her Fulbright Academic adviser. Dr. N. Anuradha is Rupel Nargunam's Ph.D. supervisor. All authors read and approved the final manuscript.

\section{Funding}

The research of the first author was supported by the Fulbright-Nehru Doctoral Research program (Award No. 2447/ DR/2019-2020).

\section{Availability of data and materials}

The data that support the findings of this study are available from Thomson Reuters Eikon Database, but restrictions apply to the availability of these data, which were used under license for the current study, and so are not publicly available. Data are however available from the authors upon reasonable request and with permission of Thomson Reuters.

\section{Declarations}

\section{Competing of interests}

The authors declare they have no conflict of interest. This research was carried out for academic purposes alone.

\section{Author details}

'Department of Statistical Science, Temple University, Philadelphia, PA 19122, USA. ${ }^{2}$ Department of Mathematics and Actuarial Science, B. S. Abdur Rahman Crescent Institute of Science and Technology, Chennai 600048, India. ${ }^{3}$ Department of Management Studies, B.S. Abdur Rahman Crescent Institute of Science and Technology, Chennai 600048, India.

Received: 31 August 2020 Accepted: 9 August 2021

Published online: 16 August 2021

\section{References}

Aggarwal R, Lucey BM (2007) Psychological barriers in gold prices? Rev Financ Econ 16(2):217-230

Alkhazali OM, Zoubi TA (2020) Gold and portfolio diversification: a stochastic dominance analysis of the Dow Jones Islamic indices. Pacific-Basin Finance J 60:101264

Al-Shiab M (2006) The predictability of the Amman stock exchange using the univariate autoregressive integrated moving average (ARIMA) model. J Econ Adm Sci 22(2):17-35

Ball CA, Torous WN, Tschoegl AE (1982) Gold and the "Weekend Effect." J Futur Mark 2(2):175-182

Baur DG (2013) The autumn effect of gold. Res Int Bus Finance 27(1):1-11

Baur DG, McDermott TK (2010) Is gold a safe haven? International evidence. J Bank Finance 34(8):1886-1898

Baur DG, McDermott TK (2016) Why is gold a safe haven? J Behav Experim Finance 10:63-71

Beckmann J, Berger T, Czudaj R (2015) Does gold act as a hedge or a safe haven for stocks? A smooth transition approach. Econ Model 48:16-24

Bollerslev T (1986) Generalized autoregressive conditional heteroskedasticity. J Econom 31 (3):307-327

Bouman S, Jacobsen B (2002) The Halloween indicator," Sell in May and go away": another puzzle. Am Econ Rev 92(5):1618-1635

Box GE, Cox DR (1964) An analysis of transformations. J R Stat Soc Ser B (methodol) 26(2):211-243

Box GEP, Jenkins GM (1970) Time series analysis, forecasting and control, holden-day, San Francisco

Box GE, Tiao GC (1975) Intervention analysis with applications to economic and environmental problems. J Am Stat Assoc 70:70-79

Box GEP, Jenkins GM, Reinsel GC, Ljung GM (2016) Time series analysis, forecasting and control, 5th edn. Wiley, New York Challa ML, Malepati V, Kolusu SNR (2018) Forecasting risk using auto regressive integrated moving average approach: an evidence from S\&P BSE Sensex. Financ Innov 4:24. https://doi.org/10.1186/s40854-018-0107-z

Challa ML, Malepati V, Kolusu SNR (2020) S\&P BSE Sensex and S\&P BSE IT return forecasting using ARIMA. Financ Innov 6(1):1-19

Chao X, Kou G, Peng Y, Alsaadi FE (2019) Behavior monitoring methods for trade-based money laundering integrating macro and micro prudential regulation: a case from China. Technol Econ Dev Econ 25(6):1081-1096

Chou RY (1988) Volatility persistence and stock valuations: some empirical evidence using GARCH. J Appl Econ 3(4):279-294

Choudhry T, Hassan SS, Shabi S (2015) Relationship between gold and stock markets during the global financial crisis: evidence from nonlinear causality tests. Int Rev Financ Anal 41:247-256

Daskalaki C, Skiadopoulos G, Topaloglou N (2017) Diversification benefits of commodities: a stochastic dominance efficiency approach. J Empir Finance 44:250-269

Dickey DA, Hasza DP, Fuller WA (1984) Testing for unit roots in seasonal time series. J Am Stat Assoc 79(386):355-367

Dong H, Guo X, Reichgelt H, Hu R (2020) Predictive power of ARIMA models in forecasting equity returns: a sliding window method. J Asset Manag 21(6):549-566

Edwards FR (1993) Taxing transactions in futures markets: objectives and effects. J Financ Serv Res 7(1):75-91

Emenogu NG, Adenomon MO, Nweze NO (2020) On the volatility of daily stock returns of Total Nigeria Plc: evidence from GARCH models, value-at-risk and backtesting. Financ Innov 6:18. https://doi.org/10.1186/s40854-020-00178-1

French KR, Schwert GW, Stambaugh RF (1987) Expected stock returns and volatility. J Financ Econ 19(1):3-29

Guha B, Bandyopadhyay G (2016) Gold price forecasting using ARIMA model. J Adv Manag Sci 4(2):117-121 
lqbal J (2017) Does gold hedge stock market, inflation and exchange rate risks? An econometric investigation. Int Rev Econ Finance 48:1-17

Jain V (2019) Empirical evidence on the existence of calendar anomalies in the market for gold and crude oil. In: Proceedings of the 2nd International Conference on Information Systems \& Management Science (ISMS). https://doi.org/10. 2139/ssin.3511451

Kamstra MJ, Kramer LA, Levi MD (2003) Winter blues: a SAD stock market cycle. Am Econ Rev 93(1):324-343

Kocaarslan B, Sari R, Gormus A, Soytas U (2017) Dynamic correlations between BRIC and US stock markets: the asymmetric impact of volatility expectations in oil, gold and financial markets. J Commod Mark 7:41-56

Kou G, Chao X, Peng Y, Alsaadi FE, Herrera-Viedma E (2019) Machine learning methods for systemic risk analysis in financial sectors. Technol Econ Dev Econ 25(5):716-742

Kumar D (2014) Return and volatility transmission between gold and stock sectors: application of portfolio management and hedging effectiveness. IIMB Manag Rev 26(1):5-16

Lean HH, Wong WK (2015) Is gold good for portfolio diversification? A stochastic dominance analysis of the Paris stock exchange. Int Rev Financ Anal 42:98-108

Lucey BM, Tully E (2006) Seasonality, risk and return in daily COMEX gold and silver data 1982-2002. Appl Financ Econ 16(4):319-333

Ma CK (1986) A further investigation of the day-of-the-week effect in the gold market. J Futur Mark 6(3):409-419

Mallikarjuna M, Rao RP (2019) Evaluation of forecasting methods from selected stock market returns. Financ Innov 5:40. https://doi.org/10.1186/s40854-019-0157-x

McCullough BD, Renfro CG (2000) Benchmarks and software standards: a case study of GARCH procedures. J Econ Soc Measur 26(1):63-77

McCullough BD, Vinod HD (1999) The numerical reliability of econometric software. J Econ Lit 1999(37):633-665

Mo D, Gupta R, Li B, Singh T (2018) The macroeconomic determinants of commodity futures volatility: evidence from Chinese and Indian markets. Econ Model 70:543-560

Mukherjee I, Goswami B (2017) The volatility of returns from commodity futures: evidence from India. Financ Innov 3:15. https://doi.org/10.1186/s40854-017-0066-9

Pariyaprasert W, Boonchuaymetta E (2018) The Halloween effect and other seasonal anomalies in the energy sector of the stock exchange of Thailand. J Risk Manag Insur 22(1):29-41

Pavaskar M, Ghosh N (2008) Commodity transaction tax: a recipe for disaster. Econ Polit Weekly 43(39):17-20

Ping PY, Miswan NH, Ahmad MH (2013) Forecasting Malaysian gold using GARCH model. Appl Math Sci 7(58):2879-2884

Samouilhan NL, Shannon G (2008) Forecasting volatility on the JSE. Invest Anal J 37(67):19-28

Schmidbauer H, Rösch A (2018) The impact of festivities on gold price expectation and volatility. Int Rev Financ Anal 58:117-131

Shakil MH, Tasnia M, Saiti B (2018) Is gold a hedge or a safe haven? An application of ARDL approach. J Econ Finance Adm Sci 23(44):60-76

Thupayagale P (2010) Evaluation of GARCH-based models in value-at-risk estimation: evidence from emerging equity markets. Invest Anal J 39(72):13-29

Todorova N (2017) The asymmetric volatility in the gold market revisited. Econ Lett 150:138-141

Wang X, Liu H, Huang S (2019) Identification of the daily seasonality in gold returns and volatilities: evidence from Shanghai and London. Resour Policy 61:522-531

Wei WWS (2006) Time series analysis: univariate and multivariate methods, 2nd edn. Pearson Addison Wesley, Boston

Xiao B, Maillebuau P (2020) The seasonal effect on the chinese gold market using an empirical analysis of the Shanghai gold exchange. Eurasian J Econ Finance 8(2):104-114

Zhang CY, Jacobsen B (2013) Are monthly seasonal real? A three century perspective. Rev Finance 17(5):1743-1785

\section{Publisher's Note}

Springer Nature remains neutral with regard to jurisdictional claims in published maps and institutional affiliations.

\section{Submit your manuscript to a SpringerOpen ${ }^{\circ}$ journal and benefit from:}

- Convenient online submission

- Rigorous peer review

- Open access: articles freely available online

- High visibility within the field

Retaining the copyright to your article

Submit your next manuscript at $\boldsymbol{s p r i n g e r o p e n . c o m ~}$ 